\title{
Analysis of the costs of a backlog project in response to recommendation 2 of the 2004 Archives and History Office Program Review Committee report
}

\author{
Laura O’Hara \\ Stanford Linear Accelerator Center \\ Stanford University \\ 2575 Sand Hill Road, MS 82 \\ Menlo Park, CA 94022 USA
}

\author{
Draft created for Departmental Use 5/5/2005 \\ Presented to 2007 SLAC Archives \& History Office Program Review, \\ SLAC, Menlo Park, CA 9/14/2007
}

\begin{abstract}
SLAC Archives and History Office (AHO) backlog of unprocessed material is over 3,000 cubic feet and growing. Because much of this material was directly transferred to off-site storage, the provenance and contents are a mystery. The costs of off-site storage, lack of knowledge of the contents, and the impending federal regulations in 2009 concerning storage facilities all suggest the need for a long-term plan for the backlog. AHO presents options to SLAC management.
\end{abstract}


DRAFT version 5/5/2005

Departmental Use Only

\section{Analysis of the costs of a backlog project in response to recommendation 2 of the 2004 Archives and History Office Program Review Committee report}

\section{Problem}

SLAC Archives and History Office (AHO) backlog of unprocessed material is over 3,000 cubic feet and growing. Because much of this material was directly transferred to off-site storage, the provenance and contents are a mystery. The costs of off-site storage, lack of knowledge of the contents, and the impending federal regulations in 2009 concerning storage facilities all suggest the need for a long-term plan for the backlog.

AHO presents these options to SLAC management:

1. Continue with the status quo, adding new accessions to OffSite Records Management, LLC (hereinafter referred to as OffSite) storage.

2. Pull the backlog back a segment at a time for box-level processing, determine what is in each box, get rid of extraneous material, and return what is left to OffSite storage.

3. Gradually retrieve the backlog for thorough, folder-level processing and then transfer to the Federal Records Center in San Bruno (hereinafter referred to as FRC) or the Archives side of the operations at the National Archives and Records Administration in San Bruno (hereinafter referred to as NARA).

4. Gradually retrieve the backlog for a combination of box-level processing with return to OffSite storage and thorough folder-level processing with transfer to FRC or NARA.

\section{Analysis}

\section{Assumptions}

The following assumptions should be kept in mind when considering the options.

- No new projects outside the normal ongoing work and supervision of this backlog project will divert AHO staff efforts.

- Cost estimates are based on current fees for OffSite and FRC/NARA.

- Current AHO staff will continue to be allocated to normal ongoing work, providing only supervision to staff added for project.

- A delay in start will probably mean a rise in costs.

- Overhead is not part of calculations.

\section{Estimates}

The following figures were estimated based on past experiences at AHO and literature research. As the project progresses, these numbers could be more closely estimated.

- Growth rate of the backlog is estimated at $200 \mathrm{cf}$ annually.

- The reduction rate for box-level processing is estimated to be $2.5 \%$. The reduction rate for folder-level processing is estimated to be $12.5 \%$.

- Box-level processing is estimated to average $1 \mathrm{hr} / \mathrm{cf}$. Actual rate will vary depending on contents of boxes. Folder-level processing is estimated to average $6 \mathrm{hrs} / \mathrm{cf}$. Actual rate will vary depending on contents of boxes; folder-level description is easiest when material arrives in labeled folders, which is sadly not the norm. 
- The $1 / 4-3 / 4$ split between box- and folder-level processing in Option 4 will probably have to be revised as knowledge is gained during the course of the project.

\section{Option summaries}

1:Continue with the status quo, adding new accessions to off-site storage. Option 1 would require no additional staff and have the least direct impact on the workload of current AHO staff. However, storage costs will increase and will include storage of material that might not be retained if material were processed. Reference on the known portion of this material will incur additional costs for retrieval and return. Reference is not be possible on the unknown material; unknown material is, and will remain, the majority of this backlog. This lack of knowledge about the majority of the material stored at OffSite will lead to the AHO staff being unable to adequately respond to reference requests. This is will be of particular concern as SLAC draws nearer to its $50^{\text {th }}$ anniversary.

2 :Pull the backlog back a segment at a time for box-level processing, determine what is in each box, get rid of extraneous material, and return what is left to OffSite storage.

Option 2 would require additional staff, probably a combination of part-time students and a project archivist to perform box-level processing. It would have minimal impact on AHO staff who will continue to be allocated to normal ongoing work, providing only supervision to staff added for project. Supplies needed would be minimal. Storage costs will be reduced as a result of box-level processing though the change will be negligible. Reference will still incur additional costs for retrieval and return. Box-level processing will make reference possible on the currently unknown material allowing AHO to better provide reference services. This level of processing would provide the minimal assistance for the $50^{\text {th }}$.

3:Gradually retrieve the backlog for thorough, folder-level processing and then transfer to FRC or NARA.

Option 3 would require an additional 2.3 FTE, probably a combination of part-time students and a project archivist to perform folder-level processing. It would have some impact on AHO staff who will continue to be allocated to normal ongoing work, providing only supervision to staff added for project. Additional space would be required to accommodate the staff and the work. Supplies needed would be the maximum of all options. Storage costs will be reduced as a result of folder-level processing. Reference will still incur additional costs for retrieval and return. Folder-level processing will make a finer level of reference possible on the currently unknown material allowing AHO to better provide reference services. This level of processing would set AHO up well for the $50^{\text {th }}$.

4: Gradually retrieve the backlog for a combination of box-level processing with return to off-site storage and thorough folder-level processing with transfer to FRC or NARA.

Option 4 would require an additional 1.1 FTE, probably a combination of part-time students and a project archivist to perform the combination of box- and folder-level processing. It would have some impact on AHO staff who will continue to be allocated to normal ongoing work, providing only supervision to staff added for project. Some supplies would be needed. Storage costs will be reduced as a result of processing. Reference will still incur additional costs for retrieval and return. Folder-level processing will make a finer level of reference possible on the currently unknown material allowing AHO to better provide reference services. This combination of processing would provide an adequate level of preparation for the $50^{\text {th }}$. 
Total costs

\begin{tabular}{|c|c|c|c|c|}
\hline & $\begin{array}{c}\text { Option 1 } \\
\text { Total cost/Year }\end{array}$ & $\begin{array}{c}\text { Option 2 } \\
\text { Total cost/Year }\end{array}$ & $\begin{array}{c}\text { Option 3 } \\
\text { Total cost/Year }\end{array}$ & $\begin{array}{c}\text { Option 4 } \\
\text { Total cost/Year }\end{array}$ \\
\hline $\mathbf{2 0 0 5}$ & 11,440 & $\$ 11,440$ & $\$ 11,440$ & $\$ 11,440$ \\
\hline $\mathbf{2 0 0 6}$ & 12,136 & $\$ 31,410-$ & $\$ 88,419-166,369$ & $\$ 45,933-74,133$ \\
& 12,832 & $\$ 43,245$ & & \\
\hline $\mathbf{2 0 0 7}$ & 13,528 & $\$ 3,106-$ & $\$ 87,843-165,793$ & $\$ 46,259-74,459$ \\
& 14,224 & $\$ 33,402-$ & $\$ 87,267-165,217$ & $\$ 46,585-74,785$ \\
\hline $\mathbf{2 0 0 8}$ & 14,920 & $\$ 34,194-$ & $\$ 86,69,115-164,065$ & $\$ 47,236-75,436$ \\
\hline $\mathbf{2 0 0 9}$ & & $\$ 46,029$ & & \\
\hline
\end{tabular}

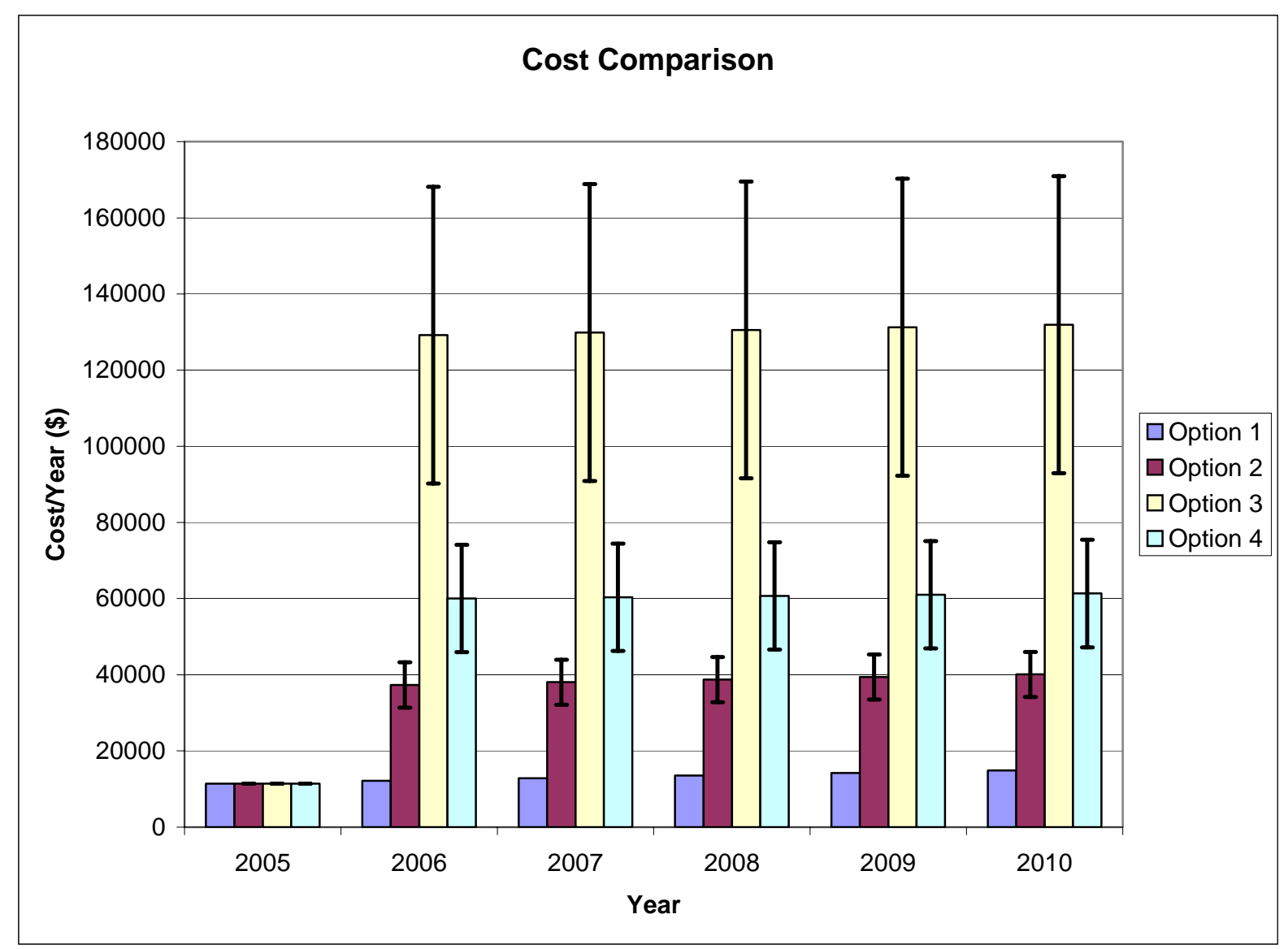


DRAFT version $5 / 5 / 2005$

Departmental Use Only

\section{Comparisons and comments}

Option 1 provides no additional benefit to AHO. Option 1 is baseline.

Option 2 provides some benefit to AHO with minimal outlay $(\$ 19,274-31,109$ per year over baseline).

Option 3 provides most benefit to AHO, but requires significant outlay $(\$ 76,283-154,233$ per year over baseline).

Option 4 provides a balance between benefit and outlay (\$33,797-62,597 per year over baseline).

Only Options 3 and 4 address the issue of the impending federal regulations in 2009 concerning storage facilities. Only Option 3 resolves this issue

Options 3 and 4 both set AHO up well to face SLAC’s 50 th anniversary in 2012.

FRC charges removal fees; once material is entered into their system storage fees are charged. If it is decided to remove material from FRC after it is in their system, this will incur additional fees unless the material is being transferred to the archives side of the NARA operations. OffSite does not currently charge removal fees.

There are no fees for material transferred to NARA, but we also transfer ownership and all control to NARA.

\section{Recommendation}

As stated at the outset, the impetus for this backlog project are the costs of off-site storage, the lack of knowledge of the contents, and the impending federal regulations in 2009 concerning storage facilities. AHO's priorities in approaching the backlog are:

1. To gain intellectual control, the current lack of knowledge has wide impact in nonquantifiable ways on all AHO activities,

2. To reduce the amount of material stored, eventually resulting in storage cost savings

3. To meet NARA's 2009 requirements

Therefore, it is recommended that AHO adopt Option 4 as the option that provides a balance of benefits without spending time on unnecessary activities. It is also recommended that careful statistics on growth rates, retrieval rates, reductions rates, and processing rates be kept in the first two years of the project so that costs can be re-evaluated based on more firm numbers.

\section{Beyond Scope}

Two future projects are also suggested.

First, the AHO should assemble statistics on use of material. This could be done by mining the reference files to compile a spreadsheet of use made over time for each accession or even to the box level. This would assist in identifying what material is most heavily used and should be kept on site. 
DRAFT version 5/5/2005

Departmental Use Only

Second, onsite holdings should be thinned by moving less used material to off site storage, whether that is OffSite or FRC. This determination would be based on the assembly of statistics suggested above. Without the statistics, it is already apparent that Directors' records, records pertaining to currently used facilities, records created by key management personnel, Wallenmeyer reports, runs of newsletters, and visual material should be retained on site. 


\section{Appendices}

Option 1 detail

Option 2 detail

Option 3 detail

Option 4 detail

OffSite fee schedule

NARA/FRC fee schedule

Spreadsheets

Bibliography 


\section{Option 1 detail}

Continue with the status quo, adding new accessions to off-site storage.

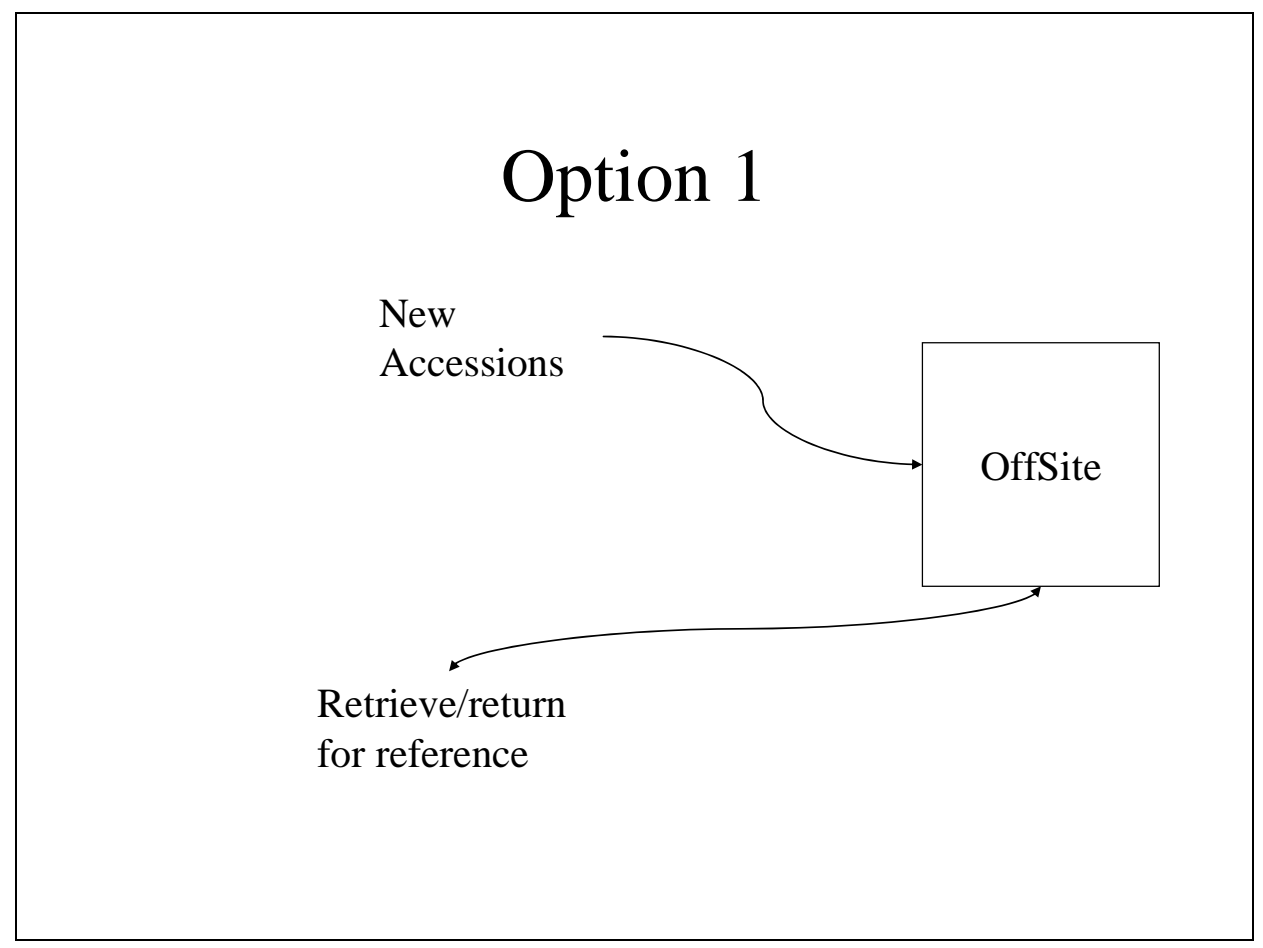

New accessions, coming in with or without any inventories are sent to OffSite Records Management, LLC. Material at OffSite is a combination of accessions with descriptions and unknown material with the majority being unknown material. We will have to pull material back in response to reference questions; this cannot be done with the unknown material. Boxes pulled for reference will be returned to OffSite.

\section{Costs}

Storage costs are estimated for the initial 3,000 cf with an estimated growth rate is of $200 \mathrm{cf}$ per year. Transportation and setup fees will vary depending on size of deposits, so setup and transportation fees for the estimated growth rate of $200 \mathrm{cf} /$ year are estimated based on shipments of $20 \mathrm{cf}$ (approximately the quantity that can presently be accommodated in the AHO holding space). A growth rate of $200 \mathrm{cf} /$ year deposited in $20 \mathrm{cf}$ increments will incur additional \$665 in setup and transportation fees. Until now, reference retrieval has been negligible (under $\$ 500 /$ year); until we know more about the contents of the majority of the boxes this is unlikely to change. All of these figures are based on the current contract with OffSite.

\begin{tabular}{|c|c|c|c|c|}
\hline & cf stored & $\begin{array}{c}\text { Storage } \\
\text { cost/Year }\end{array}$ & $\begin{array}{c}\text { Additional } \\
\text { fees/Year for } \\
\text { deposits and } \\
\text { reference } \\
\text { retrieval }\end{array}$ & Total cost/Year \\
\hline $\mathbf{2 0 0 5}$ & 3000 & 10,440 & $\$ 1,000$ & 11,440 \\
\hline
\end{tabular}


DRAFT version $5 / 5 / 2005$

Departmental Use Only

\begin{tabular}{|l|l|l|l|l|}
\hline $\mathbf{2 0 0 6}$ & 3200 & 11,136 & $\$ 1,000$ & 12,136 \\
\hline $\mathbf{2 0 0 7}$ & 3400 & 11,832 & $\$ 1,000$ & 12,832 \\
\hline $\mathbf{2 0 0 8}$ & 3600 & 12,528 & $\$ 1,000$ & 13,528 \\
\hline $\mathbf{2 0 0 9}$ & 3800 & 13,224 & $\$ 1,000$ & 14,224 \\
\hline $\mathbf{2 0 1 0}$ & 4000 & 13,920 & $\$ 1,000$ & 14,920 \\
\hline
\end{tabular}

Benefits

- Alleviates space crunch (in reality AHO has no true on-site growth space)

- Has least impact on workload of current staff

- Would not require additional staff

Summary

Option 1 would require no additional staff and have the least direct impact on the workload of current AHO staff. However, storage costs will increase and will include storage of material that might not be retained if material were processed. Reference on the known portion of this material will incur additional costs for retrieval and return. Reference is not be possible on the unknown material; unknown material is, and will remain, the majority of this backlog. This lack of knowledge about the majority of the material stored at OffSite will lead to the AHO staff being unable to adequately respond to reference requests. This is will be of particular concern as SLAC draws nearer to its $50^{\text {th }}$ anniversary. 


\section{Option 2 detail}

Pull the backlog back a segment at a time for box-level processing, determine what is in each box, get rid of extraneous material, and return what is left to OffSite storage.

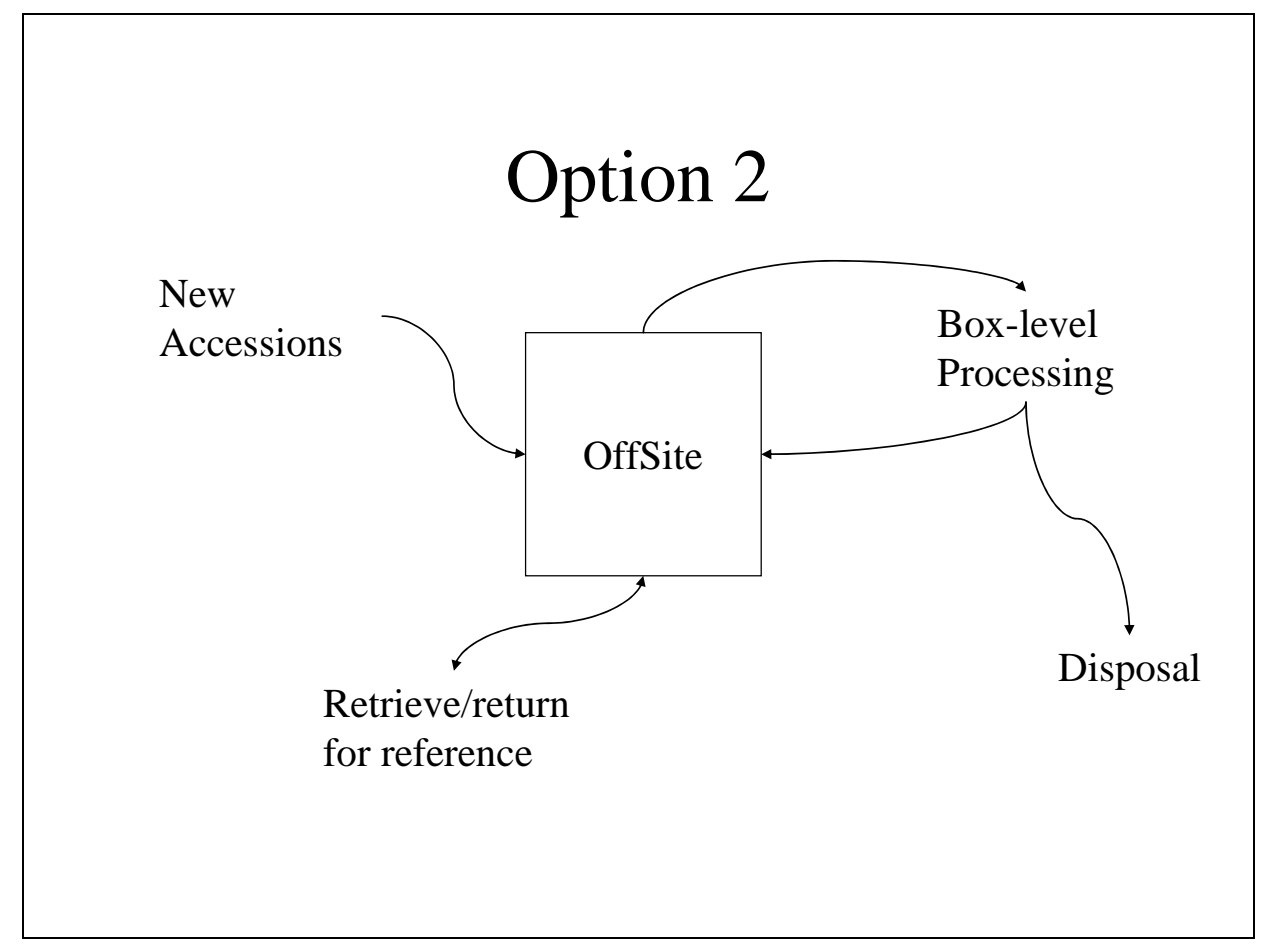

New accessions, coming in with or without any inventories are sent to OffSite Records Management, LLC. Material at OffSite is a combination of accessions with descriptions and unknown material with the majority being unknown material. We will have to pull material back in response to reference questions; this cannot be done on the unknown material. In conjunction with or in addition to, we will pull back boxes for box-level processing. Box-level processing requires minimal handling and time spent; it provides bare bones description of the material. Boxlevel processing will make some reference possible on the previously unknown material. Boxlevel processing identifies only gross disposal possibilities (whole box of non-archival material) which means there will be minimal reduction of the material stored. Once processed material is returned to OffSite.

\section{Costs}

Storage costs are estimated for the initial 3,000 cf with an estimated growth rate is of $200 \mathrm{cf}$ per year. Transportation and setup fees will vary depending on size of deposits, so setup and transportation fees for the estimated growth rate of $200 \mathrm{cf} /$ year are estimated based on shipments of $20 \mathrm{cf}$ (approximately the quantity that can presently be accommodated in the AHO holding space). A growth rate of $200 \mathrm{cf} /$ year deposited in $20 \mathrm{cf}$ increments will incur additional \$665 in setup and transportation fees. Until now, reference retrieval has been negligible (under $\$ 500 /$ year); until we know more about the contents of the majority of the boxes this is unlikely to change. All of these figures are based on the current contract with OffSite. 
DRAFT version 5/5/2005

Departmental Use Only

\begin{tabular}{|c|c|c|c|c|}
\hline & cf stored & $\begin{array}{c}\text { Storage } \\
\text { cost/Year }\end{array}$ & $\begin{array}{c}\text { Additional } \\
\text { fees/Year for } \\
\text { deposits and } \\
\text { reference } \\
\text { retrieval }\end{array}$ & $\begin{array}{c}\text { Total storage } \\
\text { cost/Year }\end{array}$ \\
\hline $\mathbf{2 0 0 5}$ & 3000 & $\$ 10,440$ & $\$ 1,000$ & $\$ 11,440$ \\
\hline $\mathbf{2 0 0 6}$ & 3200 & $\$ 11,136$ & $\$ 1,000$ & $\$ 12,136$ \\
\hline $\mathbf{2 0 0 7}$ & 3400 & $\$ 11,832$ & $\$ 1,000$ & $\$ 12,832$ \\
\hline $\mathbf{2 0 0 8}$ & 3600 & $\$ 12,528$ & $\$ 1,000$ & $\$ 13,528$ \\
\hline $\mathbf{2 0 0 9}$ & 3800 & $\$ 13,224$ & $\$ 1,000$ & $\$ 14,224$ \\
\hline $\mathbf{2 0 1 0}$ & 4000 & $\$ 13,920$ & $\$ 1,000$ & $\$ 14,920$ \\
\hline
\end{tabular}

Box-level processing of the current $3000 \mathrm{cf}$ at an estimated average rate of $1 \mathrm{hr} / \mathrm{cf}$ could take as little as one and a half years to complete if done by 1 FTE. The annual growth, estimated at 200 cf per year will add an additional 200 hours per year. Three options for project staffing are student labor (\$9-25/hr), a project archivist (\$25-40/hr), or NARA project staff (\$34-73/hr). NARA project staff is an inappropriate match to the task of box-level processing. Because of learning curves and experience, it is probably best to use a combination of student with project archivist, say approximately 2/3 student labor, 1/3 project archivist. A more experienced and skillful student would cost more, but process at a faster rate, possibly shortening the time needed. The experience of a project archivist would be required to guide the student, making appraisal decisions along the way. Additionally, students are usually not available full-time, year-round. So if the project were spread out over five years (2006-2010), factoring in the annual growth rate of 200 cf per year, it would require 800 hours per year.

\begin{tabular}{|c|c|c|c|c|}
\hline & $\begin{array}{c}\text { \# of hours } \\
\text { student labor }+ \\
\text { project archivist }\end{array}$ & $\begin{array}{c}\text { Student labor } \\
\text { cost }\end{array}$ & $\begin{array}{c}\text { Project archivist } \\
\text { cost }\end{array}$ & $\begin{array}{c}\text { Total labor } \\
\text { cost/Year }\end{array}$ \\
\hline $\mathbf{2 0 0 5}$ & na & na & na & na \\
\hline $\mathbf{2 0 0 6}$ & $535+265$ & $\$ 4,815-13,375$ & $\$ 6,625-10,600$ & $\$ 11,440-23,275$ \\
\hline $\mathbf{2 0 0 7}$ & $535+265$ & $\$ 4,815-13,375$ & $\$ 6,625-10,600$ & $\$ 11,440-23,275$ \\
\hline $\mathbf{2 0 0 8}$ & $535+265$ & $\$ 4,815-13,375$ & $\$ 6,625-10,600$ & $\$ 11,440-23,275$ \\
\hline $\mathbf{2 0 0 9}$ & $535+265$ & $\$ 4,815-13,375$ & $\$ 6,625-10,600$ & $\$ 11,440-23,275$ \\
\hline $\mathbf{2 0 1 0}$ & $535+265$ & $\$ 4,815-13,375$ & $\$ 6,625-10,600$ & $\$ 11,440-23,275$ \\
\hline
\end{tabular}

Box-level processing will incur retrieval and return costs. It is estimated that boxes will be retrieved in $20 \mathrm{cf}$ increments (approximately the quantity that can presently be accommodated in the AHO holding space) and then returned in $20 \mathrm{cf}$ increments as well. Annual retrieval will be $800 \mathrm{cf}$, while it is estimated that reduction (made possible by the removal of unneeded material during the processing) will result in a return of $780 \mathrm{cf}$ per year. Each $20 \mathrm{cf}$ increment will cost $\$ 86.50$ to either retrieve or return. Final annual fees would be $\$ 3460$ for retrieval and $\$ 3373.50$ for return for a total of $\$ 6833.50$.

Box-level processing would allow for extremely minimal if any rehousing. Supplies are estimated to be under $\$ 1,000$ per year.

\begin{tabular}{|c|c|c|c|c|c|}
\hline & $\begin{array}{c}\text { Total } \\
\text { storage } \\
\text { cost/Year }\end{array}$ & $\begin{array}{c}\text { Total labor } \\
\text { cost/Year }\end{array}$ & $\begin{array}{c}\text { Total } \\
\text { retrieval/ret } \\
\text { urn fees }\end{array}$ & $\begin{array}{c}\text { Total supply } \\
\text { cost/Year }\end{array}$ & $\begin{array}{c}\text { Total } \\
\text { cost/Year }\end{array}$ \\
\hline 2005 & $\$ 11,440$ & na & & na & $\$ 11,440$ \\
\hline
\end{tabular}


DRAFT version $5 / 5 / 2005$

Departmental Use Only

\begin{tabular}{|c|c|c|c|c|c|}
\hline $\mathbf{2 0 0 6}$ & $\$ 12,136$ & $\begin{array}{c}\$ 11,440- \\
23,275\end{array}$ & $\$ 6833.50$ & $\$ 1,000$ & $\begin{array}{c}\$ 31,410- \\
\$ 43,245\end{array}$ \\
\hline $\mathbf{2 0 0 7}$ & $\$ 12,832$ & $\$ 11,440-$ & $\$ 6833.50$ & $\$ 1,000$ & $\$ 32,106-$ \\
& & 23,275 & & & $\$ 43,941$ \\
\hline $\mathbf{2 0 0 8}$ & $\$ 13,528$ & $\$ 11,440-$ & $\$ 6833.50$ & $\$ 1,000$ & $\$ 32,802-$ \\
& & 23,275 & & & $\$ 44,637$ \\
\hline $\mathbf{2 0 0 9}$ & $\$ 14,224$ & $\$ 11,440-$ & $\$ 6833.50$ & $\$ 1,000$ & $\$ 33,498-$ \\
& & 23,275 & & & $\$ 45,333$ \\
\hline $\mathbf{2 0 1 0}$ & $\$ 14,920$ & $\$ 11,440-$ & $\$ 6833.50$ & $\$ 1,000$ & $\$ 34,194-$ \\
& & 23,275 & & & $\$ 46,029$ \\
\hline
\end{tabular}

Benefits

- Alleviates space crunch (in reality AHO has no true on-site growth space)

- Would have minimal impact on AHO staff who will continue to be allocated to normal ongoing work, providing only supervision to staff added for project

- Requires minimal supplies

- With box-level processing AHO staff will be able to provide some reference service

- Will be able to do some disposal

\section{Summary}

Option 2 would require additional staff, probably a combination of part-time students and a project archivist to perform box-level processing. It would have minimal impact on AHO staff who will continue to be allocated to normal ongoing work, providing only supervision to staff added for project. Supplies needed would be minimal. Storage costs will be reduced as a result of box-level processing though the change will be negligible. Reference will still incur additional costs for retrieval and return. Box-level processing will make reference possible on the currently unknown material allowing AHO to better provide reference services. This level of processing would provide the minimal assistance for the $50^{\text {th }}$. 
DRAFT version 5/5/2005

Departmental Use Only

\section{Option 3 detail}

Gradually retrieve the backlog for thorough, folder-level processing and then transfer to FRC or NARA.

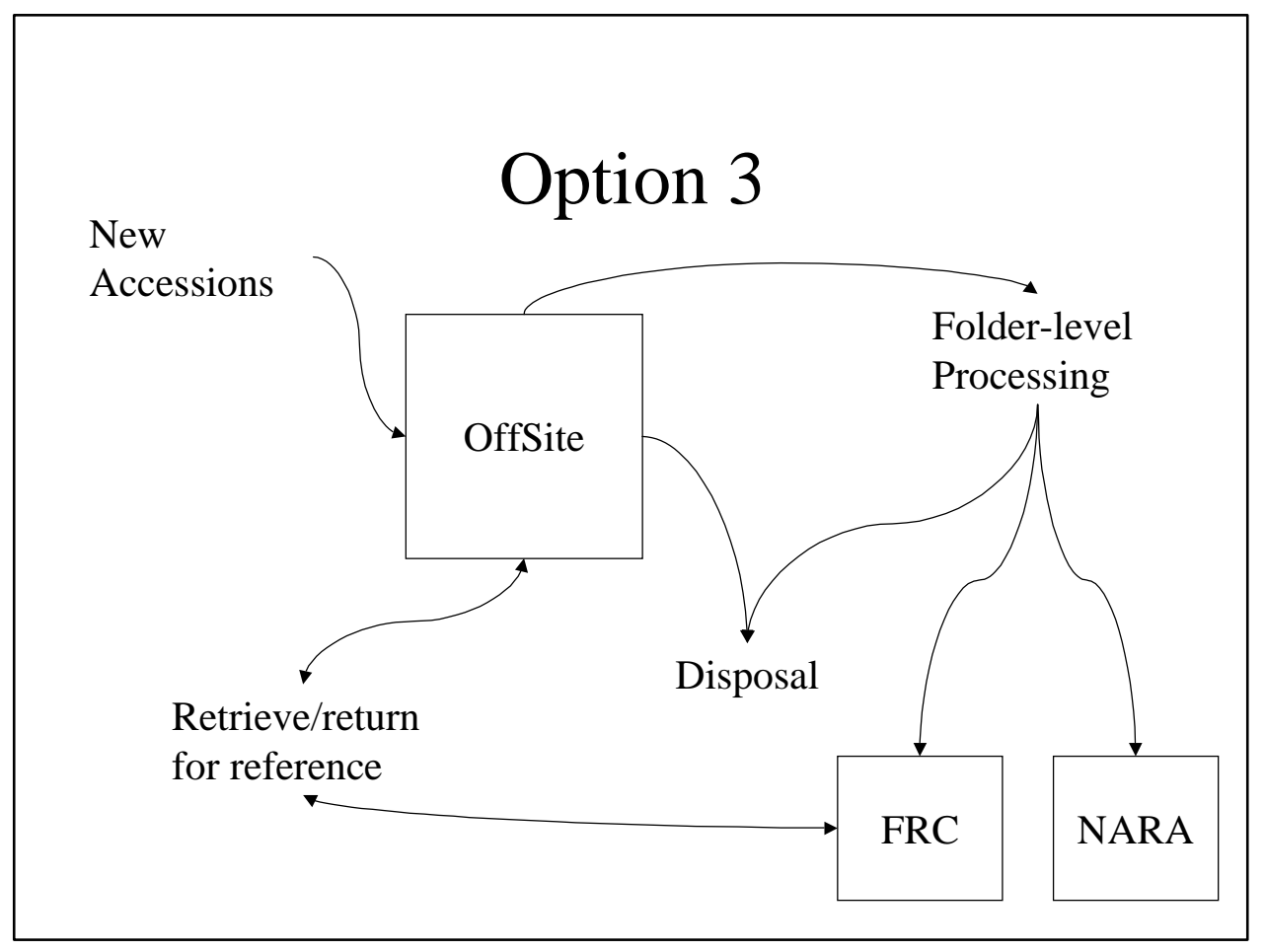

New accessions, coming in with or without any inventories are sent to OffSite Records

Management, LLC. Material at OffSite is a combination of accessions with descriptions and unknown material with the majority being unknown material. We will have to pull material back in response to reference questions; this cannot be done on the unknown material. In conjunction with or in addition to, we will pull back boxes for folder-level processing. Folder-level processing requires in-depth handling and time spent; it provides content lists to assist in identification for reference and finer-grained description of the material. Folder-level processing will make reference possible on the previously unknown material. Folder-level processing identifies additional disposal possibilities which means there will be further reduction of the material stored through identification of large item duplicates and inappropriate enclosures. Folder-level processing also includes more rehousing which usually results in a reduction in volume. Once processed to a folder level, material has the potential to be stored at the Federal Records Center (FRC) or even transferred to the national Archives (NARA). We pay for storage at the FRC (FRC storage rates are lower than OffSite's, but all other activities cost more including retrieval and removal). There are no storage fees for material transferred to NARA, but we also transfer ownership and all control to NARA.

\section{Costs}

Storage costs are estimated for the initial 3,000 cf with an estimated growth rate is of $200 \mathrm{cf}$ per year. Transportation and setup fees will vary depending on size of deposits, so setup and transportation fees for the estimated growth rate of $200 \mathrm{cf} /$ year are estimated based on shipments of $20 \mathrm{cf}$ (approximately the quantity that can presently be accommodated in the AHO holding 
space). A growth rate of $200 \mathrm{cf} /$ year deposited in $20 \mathrm{cf}$ increments will incur additional $\$ 665$ in setup and transportation fees. Until now, reference retrieval has been negligible (under $\$ 500 /$ year); until we know more about the contents of the majority of the boxes this is unlikely to change. All of these figures are based on the current contract with OffSite.

\begin{tabular}{|c|c|c|c|c|}
\hline & cf stored & $\begin{array}{c}\text { Storage } \\
\text { cost/Year }\end{array}$ & $\begin{array}{c}\text { Additional } \\
\text { fees/Year for } \\
\text { deposits and } \\
\text { reference } \\
\text { retrieval }\end{array}$ & $\begin{array}{c}\text { Total OffSite } \\
\text { storage } \\
\text { cost/Year }\end{array}$ \\
\hline $\mathbf{2 0 0 5}$ & 3000 & $\$ 10,440$ & $\$ 1,000$ & $\$ 11,440$ \\
\hline $\mathbf{2 0 0 6}$ & 3200 & $\$ 11,136$ & $\$ 1,000$ & $\$ 12,136$ \\
\hline $\mathbf{2 0 0 7}$ & 3400 & $\$ 11,832$ & $\$ 1,000$ & $\$ 12,832$ \\
\hline $\mathbf{2 0 0 8}$ & 3600 & $\$ 12,528$ & $\$ 1,000$ & $\$ 13,528$ \\
\hline $\mathbf{2 0 0 9}$ & 3800 & $\$ 13,224$ & $\$ 1,000$ & $\$ 14,224$ \\
\hline $\mathbf{2 0 1 0}$ & 4000 & $\$ 13,920$ & $\$ 1,000$ & $\$ 14,920$ \\
\hline
\end{tabular}

Folder-level processing of the current $3000 \mathrm{cf}$ plus the additional $1000 \mathrm{cf}$ anticipated to accumulate by the end of the five year project at an estimated average rate of $6 \mathrm{hrs} / \mathrm{cf}$ would take approximately eleven and a half years to complete if done by 1 FTE. To complete the project in five years would take 2.3 FTE. Three options for project staffing are student labor (\$9-25/hr), a project archivist (\$25-40/hr), or NARA project staff (\$34-73/hr). NARA project staff might be a good match for material that is identified as a candidate for transferal to the FRC, but estimates must be made by NARA personnel on a project basis so costs are not considered here. Because of learning curves and experience, it is probably best to use a combination of student with project archivist, say approximately 2/3 student labor, 1/3 project archivist. A more experienced and skillful student would cost more, but process at a faster rate, possibly shortening the time needed. The experience of a project archivist would be required to guide the student, making appraisal decisions along the way. Students are usually not available full-time, year-round.

\begin{tabular}{|c|c|c|c|c|}
\hline & $\begin{array}{c}\text { \# of hours } \\
\text { student labor }+ \\
\text { project archivist }\end{array}$ & $\begin{array}{c}\text { Student labor } \\
\text { cost }\end{array}$ & $\begin{array}{c}\text { Project archivist } \\
\text { cost }\end{array}$ & $\begin{array}{c}\text { Total labor } \\
\text { cost/Year }\end{array}$ \\
\hline $\mathbf{2 0 0 5}$ & na & na & na & na \\
\hline $\mathbf{2 0 0 6}$ & $3190+1594$ & $\$ 28710-79,750$ & $\$ 39,850-63,760$ & $\$ 65,560-143,510$ \\
\hline $\mathbf{2 0 0 7}$ & $3190+1594$ & $\$ 28710-79,750$ & $\$ 39,850-63,760$ & $\$ 65,560-143,510$ \\
\hline $\mathbf{2 0 0 8}$ & $3190+1594$ & $\$ 28710-79,750$ & $\$ 39,850-63,760$ & $\$ 65,560-143,510$ \\
\hline $\mathbf{2 0 0 9}$ & $3190+1594$ & $\$ 28710-79,750$ & $\$ 39,850-63,760$ & $\$ 65,560-143,510$ \\
\hline $\mathbf{2 0 1 0}$ & $3190+1594$ & $\$ 28710-79,750$ & $\$ 39,850-63,760$ & $\$ 65,560-143,510$ \\
\hline
\end{tabular}

Folder-level processing will incur retrieval and return costs. It is estimated that boxes will be retrieved in $20 \mathrm{cf}$ increments (approximately the quantity that can presently be accommodated in the AHO holding space) and then returned in $20 \mathrm{cf}$ increments as well. Annual retrieval will be $800 \mathrm{cf}$, while it is estimated that reduction (made possible by the removal of unneeded material during the processing) will result in a return of $700 \mathrm{cf}$ per year. Each $20 \mathrm{cf}$ increment will cost $\$ 86.50$ to either retrieve or return. Final annual fees would be $\$ 3460$ for retrieval and $\$ 3027.50$ for return for a total of $\$ 6487.50$.

After folder-level processing, some material would be eligible for storage at FRC where storage costs are 38\% lower, but new transportation and setup fees will be incurred. Transportation and 
setup fees will vary depending on size of deposits, so setup and transportation fees are estimated based on shipments of $20 \mathrm{cf}$ (approximately the quantity that can presently be accommodated in the AHO holding space). $700 \mathrm{cf} /$ year deposited in $20 \mathrm{cf}$ increments will incur additional \$5495 in setup and transportation fees. Until now, reference retrieval has been negligible (under $\$ 500 /$ year); until we know more about the contents of the majority of the boxes this is unlikely to change. All of these figures are based on the current NARA fee schedule.

\begin{tabular}{|c|c|c|c|c|}
\hline & cf stored & $\begin{array}{c}\text { Storage } \\
\text { cost/Year }\end{array}$ & $\begin{array}{c}\text { Additional } \\
\text { fees/Year for } \\
\text { deposits and } \\
\text { reference } \\
\text { retrieval }\end{array}$ & $\begin{array}{c}\text { Total FRC } \\
\text { storage } \\
\text { cost/Year }\end{array}$ \\
\hline $\mathbf{2 0 0 5}$ & na & na & na & na \\
\hline $\mathbf{2 0 0 6}$ & 700 & $\$ 1,512$ & $\$ 5,995$ & $\$ 7,507$ \\
\hline $\mathbf{2 0 0 7}$ & 1400 & $\$ 3,024$ & $\$ 5,995$ & $\$ 9,019$ \\
\hline $\mathbf{2 0 0 8}$ & 2100 & $\$ 4,536$ & $\$ 5,995$ & $\$ 10,531$ \\
\hline $\mathbf{2 0 0 9}$ & 2800 & $\$ 6,048$ & $\$ 5,995$ & $\$ 12,043$ \\
\hline $\mathbf{2 0 1 0}$ & 3500 & $\$ 7,560$ & $\$ 5,995$ & $\$ 13,555$ \\
\hline
\end{tabular}

Assuming all material pulled from OffSite and processed is then transferred to FRC, these $700 \mathrm{cf}$ would no longer incur fees at Offsite.

\begin{tabular}{|c|c|c|c|}
\hline & $\begin{array}{c}\text { OffSite storage } \\
\mathbf{\$}(\mathbf{c f})\end{array}$ & $\begin{array}{c}\text { FRC storage } \\
\mathbf{\$}(\mathbf{c f})\end{array}$ & $\begin{array}{c}\text { Total storage } \\
\text { cost/year }\end{array}$ \\
\hline $\mathbf{2 0 0 5}$ & $\$ 10,440(3000)$ & $\$ 0(0)$ & $\$ 10,440$ \\
\hline $\mathbf{2 0 0 6}$ & $\$ 8,352(2400)$ & $\$ 1,512(700)$ & $\$ 9,864$ \\
\hline $\mathbf{2 0 0 7}$ & $\$ 6,264(1800)$ & $\$ 3,024(1400)$ & $\$ 9,288$ \\
\hline $\mathbf{2 0 0 8}$ & $\$ 4,176(1200)$ & $\$ 4,536(2100)$ & $\$ 8,712$ \\
\hline $\mathbf{2 0 0 9}$ & $\$ 2,088(600)$ & $\$ 6,048(2800)$ & $\$ 8,136$ \\
\hline $\mathbf{2 0 1 0}$ & $\$ 0(0)$ & $\$ 7,560(3500)$ & $\$ 7,560$ \\
\hline
\end{tabular}

Folder-level processing would require rehousing. Supplies are estimated to be approximately $\$ 6,000$ per year.

\begin{tabular}{|c|c|c|c|c|c|}
\hline & $\begin{array}{c}\text { Total } \\
\text { storage } \\
\text { cost/Year }\end{array}$ & $\begin{array}{c}\text { Total labor } \\
\text { cost/Year }\end{array}$ & $\begin{array}{c}\text { Total } \\
\text { retrieval/ret } \\
\text { urn and } \\
\text { setup fees } \\
\text { both FRC } \\
\text { and OffSite }\end{array}$ & $\begin{array}{c}\text { Total supply } \\
\text { cost/Year }\end{array}$ & $\begin{array}{c}\text { Total } \\
\text { cost/Year }\end{array}$ \\
\hline $\mathbf{2 0 0 5}$ & $\$ 10,440$ & na & $\$ 1,000$ & na & $\$ 11,440$ \\
\hline $\mathbf{2 0 0 6}$ & $\$ 9,864$ & $\$ 65,560-$ & $\$ 6,995$ & $\$ 6,000$ & $\$ 88,419-$ \\
& & 143,510 & & & 166,369 \\
\hline $\mathbf{2 0 0 7}$ & $\$ 9,288$ & $\$ 65,560-$ & $\$ 6,995$ & $\$ 6,000$ & $\$ 87,843-$ \\
& & 143,510 & & & 165,793 \\
\hline $\mathbf{2 0 0 8}$ & $\$ 8,712$ & $\$ 65,560-$ & $\$ 6,995$ & $\$ 6,000$ & $\$ 87,267-$ \\
& & 143,510 & & & 165,217 \\
\hline $\mathbf{2 0 0 9}$ & $\$ 8,136$ & $\$ 65,560-$ & $\$ 6,995$ & $\$ 6,000$ & $\$ 86,691-$ \\
& & 143,510 & & & 164,641 \\
\hline $\mathbf{2 0 1 0}$ & $\$ 7,560$ & $\$ 65,560-$ & $\$ 6,995$ & $\$ 6,000$ & $\$ 86,115-$ \\
\hline
\end{tabular}


DRAFT version $5 / 5 / 2005$

Departmental Use Only

\begin{tabular}{|l|l|l|l|l|l|}
\hline & 143,510 & & & 164,065 \\
\hline
\end{tabular}

\section{Benefits}

- Alleviates space crunch (in reality AHO has no true on-site growth space)

- Would have some impact on AHO staff who will continue to be allocated to normal ongoing work, providing only supervision to staff added for project

- With folder-level processing AHO staff will be able to provide a finer level of reference service

- Will be able to send some of the material to the FRC, saving on storage costs

- Will be able to do more disposal

\section{Summary}

Option 3 would require an additional 2.3 FTE, probably a combination of part-time students and a project archivist to perform folder-level processing. It would have some impact on AHO staff who will continue to be allocated to normal ongoing work, providing only supervision to staff added for project. Additional space would be required to accommodate the staff and the work. Supplies needed would be the maximum of all options. Storage costs will be reduced as a result of folder-level processing. Reference will still incur additional costs for retrieval and return. Folder-level processing will make a finer level of reference possible on the currently unknown material allowing AHO to better provide reference services. This level of processing would set AHO up well for the $50^{\text {th }}$. 
DRAFT version 5/5/2005

Departmental Use Only

\section{Option 4 detail}

Gradually retrieve the backlog for a combination of box-level processing with return to off-site storage and thorough folder-level processing with transfer to FRC or NARA.

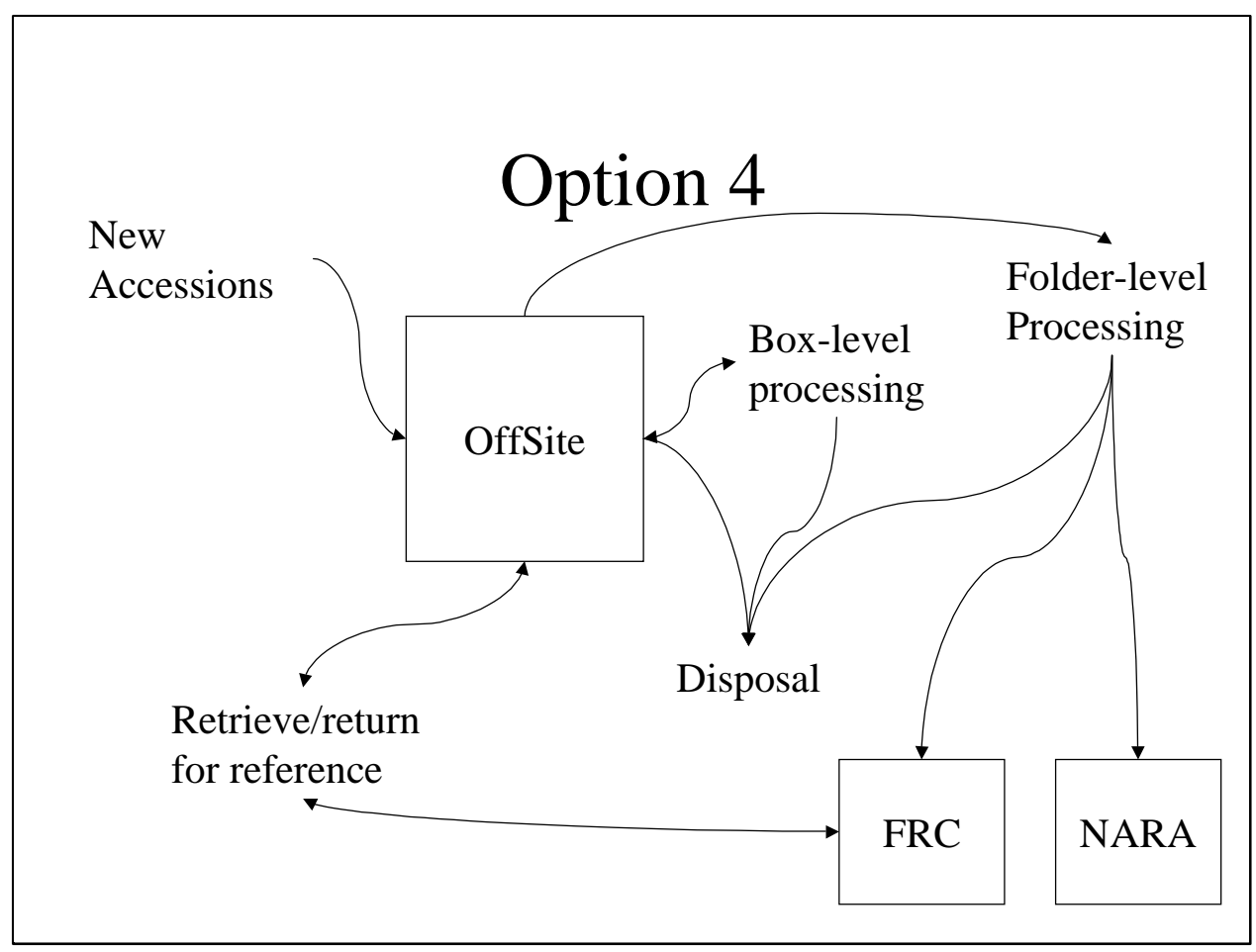

New accessions, coming in with or without any inventories are sent to OffSite Records Management, LLC. Material at OffSite is a combination of accessions with descriptions and unknown material with the majority being unknown material. We will have to pull material back in response to reference questions; this cannot be done on the unknown material. In conjunction with or in addition to, we will pull back boxes for box- and folder-level processing. Box-level processing requires minimal handling and time spent; it provides bare bones description of the material. Box-level processing will make some reference possible on the previously unknown material. Box-level processing identifies only gross disposal possibilities (whole box of nonarchival material) which means there will be minimal reduction of the material stored. Folderlevel processing requires in-depth handling and time spent; it provides content lists to assist in identification for reference and finer-grained description of the material. Folder-level processing will make reference possible on the previously unknown material. Folder-level processing identifies additional disposal possibilities which means there will be further reduction of the material stored through identification of large item duplicates and inappropriate enclosure. Folder-level processing also includes more rehousing which usually results in a reduction in volume. Once processed to a folder level, material has the potential to be stored at the Federal Records Center (FRC) or even transferred to the national Archives (NARA). We pay for storage at the FRC (FRC storage rates are lower than OffSite's, but all other activities cost more including retrieval and removal). There are no storage fees for material transferred to NARA, but we also transfer ownership and all control to NARA.

Costs 
Storage costs are estimated for the initial 3,000 cf with an estimated growth rate is of $200 \mathrm{cf}$ per year. Transportation and setup fees will vary depending on size of deposits, so setup and transportation fees for the estimated growth rate of $200 \mathrm{cf} /$ year are estimated based on shipments of $20 \mathrm{cf}$ (approximately the quantity that can presently be accommodated in the AHO holding space). A growth rate of $200 \mathrm{cf} /$ year deposited in $20 \mathrm{cf}$ increments will incur additional \$665 in setup and transportation fees. Until now, reference retrieval has been negligible (under $\$ 500 /$ year); until we know more about the contents of the majority of the boxes this is unlikely to change. All of these figures are based on the current contract with OffSite.

\begin{tabular}{|c|c|c|c|c|}
\hline & cf stored & $\begin{array}{c}\text { Storage } \\
\text { cost/Year }\end{array}$ & $\begin{array}{c}\text { Additional } \\
\text { fees/Year for } \\
\text { deposits and } \\
\text { reference } \\
\text { retrieval }\end{array}$ & $\begin{array}{c}\text { Total OffSite } \\
\text { storage } \\
\text { cost/Year }\end{array}$ \\
\hline $\mathbf{2 0 0 5}$ & 3000 & $\$ 10,440$ & $\$ 1,000$ & $\$ 11,440$ \\
\hline $\mathbf{2 0 0 6}$ & 3200 & $\$ 11,136$ & $\$ 1,000$ & $\$ 12,136$ \\
\hline $\mathbf{2 0 0 7}$ & 3400 & $\$ 11,832$ & $\$ 1,000$ & $\$ 12,832$ \\
\hline $\mathbf{2 0 0 8}$ & 3600 & $\$ 12,528$ & $\$ 1,000$ & $\$ 13,528$ \\
\hline $\mathbf{2 0 0 9}$ & 3800 & $\$ 13,224$ & $\$ 1,000$ & $\$ 14,224$ \\
\hline $\mathbf{2 0 1 0}$ & 4000 & $\$ 13,920$ & $\$ 1,000$ & $\$ 14,920$ \\
\hline
\end{tabular}

A combination of box- and folder-level processing — $3 / 4$ box level, 1/4 folder level—at an estimated average rate of $1 \mathrm{hr} / \mathrm{cf}$ for the box-level processing and an estimated average rate of 6 $\mathrm{hrs} / \mathrm{cf}$ for the folder-level processing would take 1.1 FTE to complete the project in five years. Three options for project staffing are student labor $(\$ 9-25 / \mathrm{hr})$, a project archivist $(\$ 25-40 / \mathrm{hr})$, or NARA project staff (\$34-73/hr). NARA project staff might be a good match for material that is identified as a candidate for transferal to the FRC, but estimates must be made by NARA personnel on a project basis so costs cannot be considered here. Because of learning curves and experience, it is probably best to use a combination of student with project archivist, say approximately $2 / 3$ student labor, $1 / 3$ project archivist. A more experienced and skillful student would cost more, but process at a faster rate, possibly shortening the time needed. The experience of a project archivist would be required to guide the student, making appraisal decisions along the way. Students are usually not available full-time, year-round.

\begin{tabular}{|c|c|c|c|c|}
\hline & $\begin{array}{c}\text { \# of hours } \\
\text { student labor }+ \\
\text { project archivist }\end{array}$ & $\begin{array}{c}\text { Student labor } \\
\text { cost }\end{array}$ & $\begin{array}{c}\text { Project archivist } \\
\text { cost }\end{array}$ & $\begin{array}{c}\text { Total labor } \\
\text { cost/Year }\end{array}$ \\
\hline $\mathbf{2 0 0 5}$ & na & na & na & na \\
\hline $\mathbf{2 0 0 6}$ & $1200+600$ & $\$ 10,800-30,000$ & $\$ 15,000-24,000$ & $\$ 25,800-54,000$ \\
\hline $\mathbf{2 0 0 7}$ & $1200+600$ & $\$ 10,800-30,000$ & $\$ 15,000-24,000$ & $\$ 25,800-54,000$ \\
\hline $\mathbf{2 0 0 8}$ & $1200+600$ & $\$ 10,800-30,000$ & $\$ 15,000-24,000$ & $\$ 25,800-54,000$ \\
\hline $\mathbf{2 0 0 9}$ & $1200+600$ & $\$ 10,800-30,000$ & $\$ 15,000-24,000$ & $\$ 25,800-54,000$ \\
\hline $\mathbf{2 0 1 0}$ & $1200+600$ & $\$ 10,800-30,000$ & $\$ 15,000-24,000$ & $\$ 25,800-54,000$ \\
\hline
\end{tabular}

Box- and folder-level processing will incur retrieval and return costs. It is estimated that boxes will be retrieved in $20 \mathrm{cf}$ increments (approximately the quantity that can presently be accommodated in the AHO holding space) and then returned in $20 \mathrm{cf}$ increments as well. Each 20 cf increment will cost $\$ 86.50$ to either retrieve or return from OffSite. Annual retrieval will be 800 cf; final annual fees for retrieval would be $\$ 3460$. It is estimated that box-level processing 
will result in a reduction (made possible by the removal of unneeded material during the processing) and will result in a return of 585 cf to OffSite for an annual total of \$2508.50. Folderlevel processing will result in a reduction and allow $175 \mathrm{cf}$ to be transferred to FRC. Each shipment to FRC incurs \$157 in fees for transportation and setup for an annual total of \$1413. Total annual fees for retrieval, return, and transfer is $\$ 7381.50$. All of these figures are based on the current contract with OffSite and the current NARA fee schedule.

Until now, reference retrieval has been negligible (under \$500/year); until we know more about the contents of the majority of the boxes this is unlikely to change.

As material is pulled from OffSite, processed to folder level, and transferred to FRC, it would no longer incur fees at Offsite.

\begin{tabular}{|c|c|c|c|}
\hline & $\begin{array}{c}\text { OffSite storage } \\
\mathbf{\$}(\mathbf{c f})\end{array}$ & $\begin{array}{c}\text { FRC storage } \\
\mathbf{\$}(\mathbf{c f})\end{array}$ & Total storage \\
\hline $\mathbf{2 0 0 5}$ & $\$ 10,440(3000)$ & $\$ 0(0)$ & $\$ 10,440$ \\
\hline $\mathbf{2 0 0 6}$ & $\$ 11,136(3200)$ & $\$ 0(0)$ & $\$ 11,136$ \\
\hline $\mathbf{2 0 0 7}$ & $\$ 11,084(3185)$ & $\$ 378(175)$ & $\$ 11,462$ \\
\hline $\mathbf{2 0 0 8}$ & $\$ 11,032(3170)$ & $\$ 756(350)$ & $\$ 11,788$ \\
\hline $\mathbf{2 0 0 9}$ & $\$ 10,979(3155)$ & $\$ 1134(525)$ & $\$ 12,113$ \\
\hline $\mathbf{2 0 1 0}$ & $\$ 10,927(3140)$ & $\$ 1512(700)$ & $\$ 12,439$ \\
\hline
\end{tabular}

Box-level processing would allow for extremely minimal if any rehousing while folder-level processing would require more rehousing. Supplies are estimated at \$2250 per year.

\begin{tabular}{|c|c|c|c|c|r|}
\hline & $\begin{array}{c}\text { Total } \\
\text { storage } \\
\text { cost/Year }\end{array}$ & $\begin{array}{c}\text { Total labor } \\
\text { cost/Year }\end{array}$ & $\begin{array}{c}\text { Total } \\
\text { retrieval/ret } \\
\text { urn fees }\end{array}$ & $\begin{array}{c}\text { Total supply } \\
\text { cost/Year }\end{array}$ & $\begin{array}{r}\text { Total } \\
\text { cost/Year }\end{array}$ \\
\hline $\mathbf{2 0 0 5}$ & $\$ 10,440$ & na & $\$ 1000$ & na & $\$ 11,440$ \\
\hline $\mathbf{2 0 0 6}$ & $\$ 11,136$ & $\begin{array}{c}\$ 25,800- \\
54,000\end{array}$ & $\$ 6747$ & $\$ 2250$ & $\$ 45,933-$ \\
& $\$ 11,462$ & $\$ 25,800-$ & $\$ 6747$ & $\$ 2250$ & $\$ 4,133$ \\
\hline $\mathbf{2 0 0 7}$ & $\$ 11,788$ & $\$ 25,800-$ & $\$ 6747$ & $\$ 2250$ & 74,459 \\
\hline $\mathbf{2 0 0 8}$ & $\$ 12,113$ & $\$ 25,800-$ & $\$ 6747$ & $\$ 2250$ & $\$ 46,585-$ \\
& & 54,000 & & & $\$ 44,785$ \\
\hline $\mathbf{2 0 0 9}$ & $\$ 12,439$ & $\$ 25,800-$ & $\$ 6747$ & $\$ 2250$ & 75,110 \\
\hline $\mathbf{2 0 1 0}$ & & 54,000 & & & $\$ 47,236-$ \\
& & & & & 75,436 \\
\hline
\end{tabular}

Benefits

- $\quad$ Alleviates space crunch (in reality AHO has no true on-site growth space)

- Would have some impact on AHO staff who will continue to be allocated to normal ongoing work, providing only supervision to staff added for project

- With a combination of box- and folder-level processing, staff will have discretion over the level of description saving time and labor without sacrificing significant control

- AHO staff will be able to provide reference service

- Will be able to send some of the material to the FRC, saving on storage costs

- Will be able to do some disposal 
DRAFT version 5/5/2005

Departmental Use Only

\section{Summary}

Option 4 would require an additional 1.1 FTE, probably a combination of part-time students and a project archivist to perform the combination of box- and folder-level processing. It would have some impact on AHO staff who will continue to be allocated to normal ongoing work, providing only supervision to staff added for project. Some supplies would be needed. Storage costs will be reduced as a result of processing. Reference will still incur additional costs for retrieval and return. Folder-level processing will make a finer level of reference possible on the currently unknown material allowing AHO to better provide reference services. This combination of processing would provide an adequate level of preparation for the $50^{\text {th }}$. 
DRAFT version 5/5/2005

Departmental Use Only

\section{Insert}

- OffSite fee schedule

- NARA/FRC fee schedule

- Spreadsheets 
DRAFT version $5 / 5 / 2005$

Departmental Use Only

\section{Bibliography}

Abraham, Terry. "Oliver W. Holmes Revisited: Five Levels of Arrangement and Description in Practice.” American Archivist 54 (Summer 1991): 370-377. [Meissner]

Abraham, Terry. ; Balzarini, Stephen E. ; Frantilla, Anne. "What is backlog is prologue: a measurement of archival processing.” The American Archivist v. 48 (Winter '85) p. 3144.[LibLit] [Congressional Papers Roundtable, SAA, March 1996] [Meissner]

Archives \& Archivists listserv thread on Cost to process a collection, February 2005.

Archives \& Archivists listserv thread on Backlog, March 2005.

Association of Research Libraries Special Collections Task Force working conference "Exposing Hidden Collections,” 9/8-9/2003 webite.

Boles, Frank .Draft of paper to be delivered at 2004 SAA meeting, for session "Twenty Years Later and the Box is Blacker than Ever.” [Meissner]

Council for Museums, Archives, and Libraries. Benchmarks in Collection Care for Museums, Archives and Libraries: A Self Assessment Checklist ([n.p.], 2003). [Meissner]

Davis, W. N. “Budgeting for Archival Processing.” American Archivist 43 (Spring 1980). [Meissner]

Desnoyers, Megan. “When is it Processed?.” In Daniels, Maygene F., and Walch, Timothy, eds. A Modern Archives Reader (Washington, D.C.: National Archives Trust Fund Board, 1984): 309325. (Originally published in Midwestern Archivist VII:2 (1982).) [Meissner]

Erickson, Paul, and Schuster, Robert. "Beneficial Shocks: The Place of Processing-Cost Analysis in Archival Administration." American Archivist 58 (Winter 1995): 32-53.

Greene, Mark A., Dennis Meissner. “More Product, Less Process: Pragmatically Revamping Traditional Processing Approaches to Deal with Late $20^{\text {th }}$-Century Collections,” NHPRC Archival Fellows Symposium Paper, boston, 6/11/2004.

Hackbart-Dean, Pam. ; De Catanzaro, Christine. "The Strongest Link: The Management and Processing of Archival Collections.” Archival Issues v. 27 no2 (2002) p. 125-36 [LibLit] [Meissner]

Haller, Uli. “Processing for access.” The American Archivist v. 48 (Fall '85) p. 400-15 [LibLit]

Haller, Uli. "Variations in the processing rates on the Magnuson and Jackson senatorial papers." The American Archivist v. 50 (Winter '87) p. 100-9 [LibLit] [Congressional Papers Roundtable, SAA, March 1996] [Meissner]

Hite, Richard W. ; Linke, Daniel J. “A statistical summary of appraisal during processing: a case study with manuscript collections. at the Western Reserve Historical Society" Archival Issues v. 17 no1 (1992) p. 23-9 [LibLit] 
DRAFT version 5/5/2005

Departmental Use Only

Holmes, Oliver W. “Archival Arrangement-Five Different Options at Five Different Levels.” In Daniels, Maygene F., and Walch, Timothy, eds. A Modern Archives Reader (Washington, D.C.: National Archives Trust Fund Board, 1984): 162-180. (Originally published in American Archivist 27 (Jan. 1964).) [Meissner]

Jones, Barbara M. , compiler. "Hidden Collections, Scholarly Barriers: Creating Access To Unprocessed Special Collections Materials in North America's Research Libraries--A White Paper for the Association of Research Libraries Task Force on Special Collections” (June 2003) at http://www.arl.org/collect/spcoll/ehc/HiddenCollsWhitePaperJun6.pdf (accessed 19 May 2004). [Meissner]

Lundy, M. Winslow. ; Hollis, Deborah R. "Creating Access to Invisible Special Collections: Using Participatory Management to Reduce a Backlog.” Journal of Academic Librarianship v. 30 no6 (November 2004) p. 466-75 [LibLit]

Lynch , Karen Temple and Thomas E. Lynch. "Rates of Processing Manuscripts and Archives," the Midwestern Archivist 50 (1987) 25-34. [Congressional Papers Roundtable, SAA, March 1996] [Meissner]

Maher, William J. "Measurement and Analysis of Processing Costs in Academic Archives," College and Research Libraries 43 (January 1982) 59-67. [Congressional Papers Roundtable, SAA, March 1996] [Meissner]

Millar, Laura. "The spirit of total archives: seeking a sustainable archival system.” Archivaria no47 (Spring 1999) p. 46-65 [LibLit]

Rawlings, Jennifer L. Processing twentieth century collections : a case study of the Charles Kuralt papers. 1999. (MSLS) Univ of NC at Chapel Hill. [LibLit]

Schultz, Charles. "Report on Case Studies on Manuscript Administration-Costs of Acquiring, Processing, and Housing Collections.” Unpublished report to the Society of American Archivists' Committee on Personal Papers and Manuscripts ([n.p.], Sept. 28, 1976).

Sink, Robert. "Appraisal: the process of choice. field testing the "black box" appraisal model at NYPL” The American Archivist v. 53 (Summer '90) p. 452-8 [LibLit]

Slotkin, Helen W., and Lynch Karen T. "An Analysis of Processing Procedures: The Adaptable Approach.” American Archivist 45 (1982): 155-163.

Stout, Leon J. "Doing it by the numbers: standard statistics for describing archives.” The American Archivist v. 53 (Winter '90) p. 68-75 [LibLit]

Thompson, D. Claudia. “What is Processed?” paper at Western Round-Up, Las Vegas, 4/13$17 / 2005$.

Underhill, Karen J. ; Palmer, Bruce. “Archival Content Anywhere@Anytime. At Northern Arizona University” Internet Reference Services Quarterly v. 7 no1/2 (2002) p. 19-30 [LibLit]

Vargas, Mark A. "Using a Third-Party Vendor for Off-Site Storage of Library Materials: A Case Study of the Byrne Memorial Library, Saint Xavier University," Library Administration \& Management v.19, no.1 (Winter 2005) p.26-30. 
DRAFT version $5 / 5 / 2005$

Departmental Use Only

Wojcik, Caryn.”Appraisal, Reappraisal, and Deaccessioning.” Archival Issues v. 27 no2 (2002) p. 151-60 [LibLit] 